\title{
OPEN Differences in serum protein electrophoretic pattern in dogs naturally infected with Babesia gibsoni and Babesia canis
}

\begin{abstract}
Csilla Tóthová ${ }^{1 \bowtie}$, Martina Karasová2 ${ }^{2}$ Lucia Blaňarová ${ }^{3}$, Mária Fialkovičová2 \& Oskar Nagy ${ }^{1}$
Canine babesiosis may cause several hematological and biochemical changes, but only limited studies are available regarding the possible differences of changes in animals infected by different Babesia parasites. The study focused on the evaluation of the differences in serum protein electrophoretic pattern between dogs naturally infected with B. gibsoni (17 dogs) and B. canis ( 40 dogs). The mean values of total proteins, $\beta_{1}{ }^{-}, \beta_{2}$ - and $\gamma$-globulins were in dogs infected with $B$. gibsoni significantly higher $(P<0.05$ and $P<0.001)$ than in dogs infected with $B$. canis. The relative concentrations of albumin, $\alpha_{1-}, \alpha_{2}$-globulins and the $A / G$ ratios were in the $B$. gibsoni infected dogs significantly lower $(P<0.001)$, no significant differences were found in the relative concentrations of $\beta_{1}$ - and $\beta_{2}$-globulins. Significant differences were found in most of the evaluated parameters when comparing the results in relation to the form of $B$. canis infection to $B$. gibsoni infection. Hematological indices showed significant differences between dogs infected with $B$. gibsoni and the complicated form of $B$. canis infection. In conclusion, the obtained results suggest differences in the changes of serum protein electrophoretic pattern between dogs infected with both Babesia species and thus, in the response to the infection caused by various Babesia parasites.
\end{abstract}

Canine babesiosis is an important widespread haemoprotozoan parasitic infection documented principally throughout Asia, Africa, Japan and South America, but recently there has been an increase in the rate of transmission of such diseases which were previously considered as exotic or atypical for the dogs in Europe ${ }^{1}$. Infections have been reported also from various regions of Australia and North America ${ }^{2}$. The clinical manifestation, severity and the course of the disease primarily depend on the species of Babesia parasite causing infection ${ }^{3}$. While the Babesia canis (B. canis) infection is characterized by acute manifestation of clinical signs (marked hemolytic anaemia, hemoglobinuria, pale mucous membranes, icterus, consistent high fever), the clinical signs resulting from the infection with Babesia gibsoni (B. gibsoni) are less conspicuous than those observed in dogs infected with $B$. canis, and can vary widely from chronic or subclinical to fulminant disease resulting in multiple organ failure ${ }^{4}$. Hyper-acute states are rare, while chronic infections with lymph node enlargement, weight loss, protein-losing nephropathy, renal failure and immune-mediated hemolytic anemia are more common ${ }^{5}$. Dogs with chronic infections often do not show clinical signs of the disease (the so called carrier dogs), which is probably the result of the inability of the immune system to eliminate the infection ${ }^{6,7}$. Furthermore, PCR positive dogs without clinical signs of the disease and in the absence of microscopic parasitaemia have been also reported, probably caused by low parasitaemia below the microscopic detection limit and problematic detection of smallsized parasites in the blood smears ${ }^{8}$. Infections by B. gibsoni have been described predominantly in American pit bull terrier-type dogs in the absence of tick vectors, usually due to biting and fighting between infected and non-infected dogs, transmission by blood transfusions, as well as transplacental transmission ${ }^{9,10}$.

The pathophysiology and immunopathogenesis of the disease caused by $B$. canis is well described and documented in a large number of available reports, but the pathogenesis of $B$. gibsoni infection is incompletely understood. It was stated previously that the parasitic infection with Babesia induces a systemic inflammatory response and is associated with marked release of inflammatory cytokines ${ }^{11,12}$. In response to inflammatory cytokine secretion, increased production of acute phase proteins, particularly C-reactive protein were found in dogs

${ }^{1}$ Clinic of Ruminants, University of Veterinary Medicine and Pharmacy, Komenského 73, 04181 Kosice, Slovak Republic. ${ }^{2}$ Clinic of Small Animals, University of Veterinary Medicine and Pharmacy, Komenského 73, 041 81 Kosice, Slovak Republic. ${ }^{3}$ Parasitological Institute, Slovak Academy of Sciences, Hlinkova 3, 04181 Kosice, Slovak Republic. ${ }^{\circledR}$ email: csilla.tothova@uvlf.sk 


\begin{tabular}{|c|c|c|c|c|c|}
\hline \multirow[b]{3}{*}{ Variables } & \multicolumn{4}{|c|}{ Dogs infected with } & \multirow[b]{3}{*}{$P$ value } \\
\hline & \multirow[b]{2}{*}{ B. gibsoni } & \multirow[b]{2}{*}{ B. canis } & \multicolumn{2}{|l|}{ B. canis } & \\
\hline & & & UC & C & \\
\hline Albumin & $34.9 \pm 6.6$ & $44.8 \pm 6.2^{*}$ & $46.9 \pm 5.5^{c}$ & $45.5 \pm 5.8$ & $<0.001$ \\
\hline$\alpha_{1}$-Globulins & $3.5 \pm 0.6$ & $5.1 \pm 1.2^{*}$ & $4.8 \pm 0.9^{c}$ & $5.7 \pm 1.3^{c}$ & $<0.001$ \\
\hline$a_{2}$-Globulins & $11.5 \pm 1.8$ & $16.6 \pm 4.0^{*}$ & $16.8 \pm 4.0^{c}$ & $16.3 \pm 4.0^{c}$ & $<0.001$ \\
\hline$\beta_{1}$-Globulins & $11.2 \pm 2.7$ & $12.9 \pm 4.1$ & $10.9 \pm 3.0$ & $16.2 \pm 3.7^{b}$ & $<0.001$ \\
\hline$\beta_{2}$-Globulins & $11.1 \pm 2.0$ & $11.1 \pm 2.7$ & $11.3 \pm 2.9$ & $10.9 \pm 2.3$ & n.s \\
\hline$\gamma$-Globulins & $27.8 \pm 5.9$ & $9.4 \pm 2.5^{\star}$ & $9.5 \pm 2.9^{c}$ & $9.4 \pm 1.7^{\mathrm{c}}$ & $<0.001$ \\
\hline $\mathrm{A} / \mathrm{G}$ & $0.55 \pm 0.16$ & $0.83 \pm 0.21^{\star}$ & $0.90 \pm 0.19^{c}$ & $0.72 \pm 0.19$ & $<0.001$ \\
\hline
\end{tabular}

Table 1. Differences in the relative concentrations of serum protein fractions (\%) and albumin/globulin ratio $(\mathrm{A} / \mathrm{G})$ between dogs infected with $B$. gibsoni and B. canis (mean $\pm \mathrm{SD}$ ). $P$ value-significance of the analysis of variance, n.s., not significant; A/G, albumin/globulin ratio; UC, uncomplicated form; C, complicated form. *Significance of the differences between $B$. gibsoni and $B$. canis infected dogs at $P<0.001$. ${ }^{\text {b,c }}$ Significance of the differences between B. gibsoni and B. canis UC and C infected dogs: ${ }^{b} P<0.01$; ${ }^{c} P<0.001$.

\begin{tabular}{|c|c|c|c|c|c|}
\hline \multirow[b]{3}{*}{ Variables } & \multicolumn{4}{|c|}{ Dogs infected with } & \multirow[b]{3}{*}{$P$ value } \\
\hline & \multirow[b]{2}{*}{ B. gibsoni } & \multirow[b]{2}{*}{ B. canis } & \multicolumn{2}{|l|}{ B. canis } & \\
\hline & & & UC & C & \\
\hline $\mathrm{TP}$ & $77.2 \pm 6.7$ & $56.2 \pm 7.6^{\dagger}$ & $58.0 \pm 7.2^{c}$ & $53.1 \pm 7.6^{c}$ & $<0.001$ \\
\hline Albumin & $26.7 \pm 3.9$ & $25.3 \pm 5.1$ & $27.1 \pm 4.3$ & $22.1 \pm 5.0^{\mathrm{a}}$ & $<0.01$ \\
\hline$a_{1}$-Globulins & $2.7 \pm 0.4$ & $2.8 \pm 0.5$ & $2.7 \pm 0.4$ & $3.0 \pm 0.5$ & n.s \\
\hline$a_{2}$-Globulins & $8.8 \pm 1.4$ & $9.4 \pm 2.7$ & $9.8 \pm 2.7$ & $8.7 \pm 2.5$ & n.s \\
\hline$\beta_{1}$-Globulins & $8.7 \pm 2.6$ & $7.2 \pm 2.3^{*}$ & $6.3 \pm 1.9^{\mathrm{b}}$ & $8.6 \pm 2.4$ & $<0.01$ \\
\hline$\beta_{2}$-Globulins & $8.6 \pm 1.7$ & $6.3 \pm 1.8^{\dagger}$ & $6.6 \pm 2.0^{\mathrm{b}}$ & $5.7 \pm 1.2^{\mathrm{c}}$ & $<0.001$ \\
\hline$\gamma$-Globulins & $21.7 \pm 6.3$ & $5.3 \pm 1.6^{\dagger}$ & $5.5 \pm 1.8^{c}$ & $5.0 \pm 1.2$ & $<0.001$ \\
\hline
\end{tabular}

Table 2. Differences in the concentrations of total serum proteins (TP, $g / l)$ and absolute values of protein fractions ( $\mathrm{g} / \mathrm{l}$ ) between dogs infected with B. gibsoni and B. canis (mean $\pm \mathrm{SD})$. P value-significance of the analysis of variance, n.s., not significant; TP, total proteins; UC, uncomplicated form; C, complicated form. ${ }^{*, \dagger}$ Significance of differences between $B$. gibsoni and B. canis infected dogs: ${ }^{\star} P<0.05,{ }^{\dagger} P<001$. ${ }^{\mathrm{a}, \mathrm{b}, \mathrm{c}}$ Significance of the differences between $B$. gibsoni and B. canis UC and C infected dogs: ${ }^{a} P<0.05 ;{ }^{b} P<0.01 ;{ }^{c} P<0.001$.

naturally infected with $B$. canis at the time of presentation to the veterinary hospital, and recently also in dogs experimentally infected with B. gibson $i^{13-15}$. Furthermore, the infection with B. canis in dogs may cause marked alterations also in the electrophoretic pattern of serum proteins ${ }^{16}$, but the changes in the protein pattern in dogs infected with B. gibsoni remain undetermined. Many studies presented in the literature concerning babesiosis in dogs are focused on the issues of pathogenesis, clinical picture, some hematological and biochemical parameters, therapy and prevention. However, to our knowledge no studies have investigated the possible differences in the changes in haematological indices and serum protein profile in dogs suffering from babesiosis with regard to differences in the pathogenesis of various Babesia parasites. Therefore the study was focused on the evaluation of the alterations in the serum protein pattern in dogs naturally infected with B. gibsoni, and to compare the results with the values obtained in dogs infected with $B$. canis including also the comparison of uncomplicated and complicated forms of the disease. Because of the primary and main laboratory abnormalities in Babesia infections are hematological alterations, we evaluated the changes in some hematological parameters as well.

\section{Results}

The results of serum protein analyses and the hematological data are shown in Tables 1, 2 and 3. Representative examples of the electrophoretograms from both groups of dogs are shown in Fig. 1a-c.

The relative mean concentration of albumin was significantly lower in the dogs infected with $B$. gibsoni (about $10 \%$ ) when compared to the mean value obtained in the dogs infected with $B$. canis (Table $1 ; P<0.001$ ). Similarly, the dogs infected with $B$. gibsoni had significantly lower relative concentrations of $\alpha_{1}$ - and $\alpha_{2}$-globulins $(P<0.001)$. A double $\alpha_{2}$-zone was found in nine out of seventeen with B. gibsoni infected dogs (more than $\left.50 \%\right)$ and in six out of forty dogs (15\%) infected with B. canis (Fig. 1b). Non-significantly lower mean relative value of $\beta_{1}$-globulins was found in dogs infected with $B$. gibsoni, the mean relative concentrations of $\beta_{2}$-globulins showed no significant differences between the two groups of dogs and the mean values were similar. The dogs infected with B. gibsoni were found to have significantly higher relative mean values of $\gamma$-globulins (approximately threefold higher) than those infected with $B$. canis $(P<0.001)$. The $\gamma$-globulin pattern were in the dogs infected with $B$. gibsoni characterized by markedly higher values observable as higher and broad peaks on the 


\begin{tabular}{|l|l|l|l|l|l|}
\hline \multirow{2}{*}{ Variables } & \multicolumn{2}{|l|}{ Dogs infected with } & \multicolumn{2}{l|}{ B. canis } & \multirow{2}{*}{} \\
\cline { 2 - 6 } & \multirow{2}{*}{ B. gibsoni } & B. canis & UC & C & P value \\
\hline RBC & $4.41 \pm 1.41$ & $5.27 \pm 1.72$ & $5.88 \pm 1.13^{\mathrm{b}}$ & $4.24 \pm 2.06$ & $<0.001$ \\
\hline $\mathrm{Hb}$ & $9.71 \pm 3.07$ & $11.54 \pm 3.88$ & $13.07 \pm 2.77^{\mathrm{b}}$ & $8.97 \pm 4.18$ & $<0.001$ \\
\hline $\mathrm{PCV}$ & $0.29 \pm 0.09$ & $0.32 \pm 0.11$ & $0.37 \pm 0.08^{\mathrm{a}}$ & $0.24 \pm 0.12$ & $<0.001$ \\
\hline
\end{tabular}

Table 3. Differences in the values of hematological parameters between dogs infected with $B$. gibsoni and $B$. canis (mean $\pm \mathrm{SD}$ ). $P$ value-significance of the analysis of variance, n.s., not significant; RBC, red blood cells; $\mathrm{Hb}$, hemoglobin; PCV, packed cell volume; UC, uncomplicated form; C, complicated form. ${ }^{\text {a,b }}$ Significance of the differences between B. gibsoni and B. canis UC and C infected dogs: ${ }^{\mathrm{a}} P<0.05 ;{ }^{\mathrm{b}} P<0.01$.
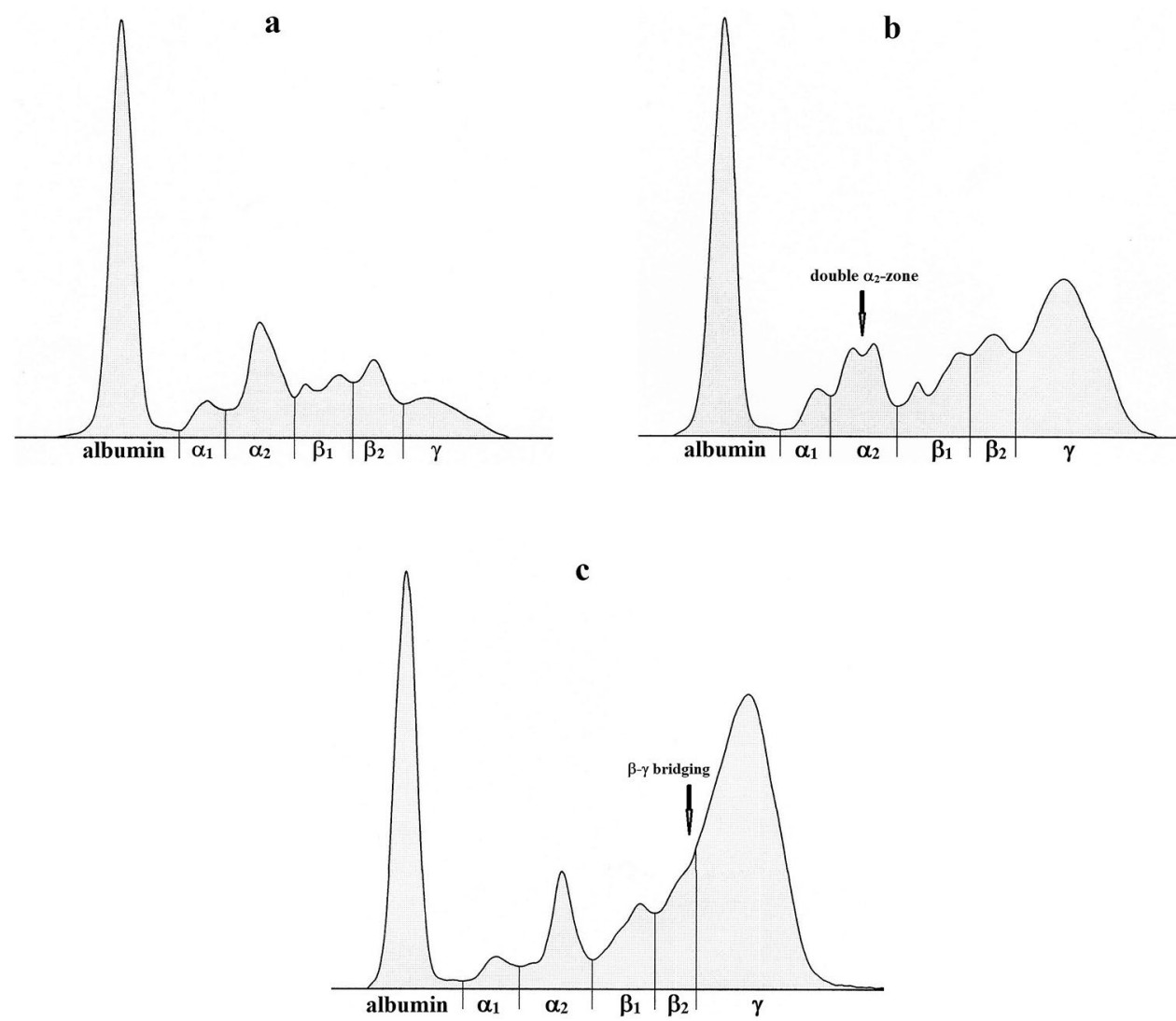

Figure 1. Representative electrophoretograms characterizing the differences in serum protein fractions in dogs infected with B. canis (a) and B. gibsoni $(\mathbf{b}, \mathbf{c})$.

electrophoretogram. Furthermore, a $\beta-\gamma$ bridging with no clear separation of these fractions was observable in two from seventeen dogs infected with $B$. gibsoni (Fig. 1c). The A/G ratio was significantly lower in the group of dogs infected with B. gibsoni than in animals infected with B. canis $(P<0.001)$. Differences found in the results of the relative concentrations of the evaluated variables between the groups of dogs were significant $(P<0.001)$, except for $\beta_{2}$-globulins. Compared to dogs with $B$. gibsoni infection, the mean relative values of albumin, $\alpha_{1}$-, $\alpha_{2}$-globulins and $\mathrm{A} / \mathrm{G}$ ratio were significantly higher $(P<0.001)$ in dogs with uncomplicated form of $B$. canis infection. In dogs with complicated form of infection significantly higher mean relative values were found in $\alpha_{1^{-}}(P<0.001), \alpha_{2}-(P<0.001)$ and $\beta_{1}$-globulins $(P<0.01)$. In both forms of $B$. canis infections the relative mean values of $\gamma$-globulins were significantly lower $(P<0.001)$ than in dogs with $B$. gibsoni infection.

Significantly higher mean total serum protein concentration was recorded in dogs infected with $B$. gibsoni when compared with the $B$. canis infected animals $(P<0.001)$ and this difference is more than $20 \mathrm{~g} / \mathrm{l}$ (Table 2). The analyses of the absolute concentrations of protein fractions showed no significant differences in the mean albumin, $\alpha_{1}$ - and $\alpha_{2}$-globulins between the two groups of dogs. Significantly higher mean values in dogs infected with $B$. gibsoni were observed for $\beta_{1^{-}}, \beta_{2^{-}}$and $\gamma$-globulins $(P<0.05, P<0.001$ and $P<0.001$, respectively). The difference in the mean concentration of $\gamma$-globulins between both groups of dogs was more than $16 \mathrm{~g} / \mathrm{l}$. Except for $\alpha_{1}$-and $\alpha_{2}$-globulins the differences found in the means of the absolute concentrations of TP and protein 
fractions between dogs infected with B. gibsoni and the two forms of $B$. canis infections were significant $(P<0.01$ and $P<0.001)$. The means of TP and absolute values of $\beta_{1^{-}}, \beta_{2^{-}}$and $\gamma$-globulins were significantly lower in dogs with uncomplicated form of $B$. canis infection than in dogs with $B$. gibsoni infection $(P<0.01$ and $P<0.001)$. In dogs with complicated form of infection significantly lower means were found in $\mathrm{TP}(P<0.001)$, albumin $(P<0.05)$ and $\beta_{2}$-globulins $(P<0.001)$.

The evaluation of hematological parameters showed differences between the groups of dogs characterized by non-significantly lower mean number of red blood cells, lower mean concentration of hemoglobin and lower mean PCV value in dogs infected with B. gibsoni (Table 3). Differences found in the results of the relative concentrations of the hematological variables between dogs infected with $B$. gibsoni and the two forms of $B$. canis infections were significant $(P<0.001)$. The differences in the means of RBC, Hb and PCV were significant between the dogs infected with $B$. gibsoni and the complicated form of $B$. canis infection $(P<0.01, P<0.01$ and $P<0.05$, respectively).

\section{Discussion}

Babesiosis is one of the most important globally extended infections of dogs. Infections caused with $B$. canis are more common, but recently, due to global climate changes, $B$. gibsoni has been recognized as an important pathogen that affects dogs also in Middle Europe. Cases have been reported in Germany, Croatia, as well as from Serbia and Poland ${ }^{1,17,18}$. The infection with B. gibsoni mostly causes mild clinical signs which are manifested as a subclinical infection or associated only with weight loss and weakness ${ }^{7}$. Furthermore, chronic infections may be also observed that usually are completely asymptomatic or may be characterized by intermittent fever, lethargy, and weight loss ${ }^{19,20}$. In some cases, after initial parasitemia, the immune system may not totally eradicate the infection, and a chronic carrier state remains without clinical signs of the disease ${ }^{21}$. Relapses may occur months to years later and many complications may develop, including glomerulonephritis and polyarthritis ${ }^{22}$.

Hemolytic anemia is the predominant manifestation of babesiosis ${ }^{23}$. A significant decrease of total erythrocyte count and hemoglobin was reported in canine babesiosis by several authors indicating anemia in the affected $\operatorname{dogs}^{24-26}$. Although in dogs infected with B. gibsoni the parasitemia is usually mild, but anemia can be severe ${ }^{21}$. In earlier studies, hemoglobinuria with a severe hemolytic anemia was not observed in dogs naturally or experimentally infected with B. gibsoni $i^{27,28}$. In a further study, dogs experimentally infected with B. gibsoni developed mild anemia, which was transient and resolved by the day 17 after the infection ${ }^{15}$. On the other hand, Ishimine et al. ${ }^{4}$ observed severe hemolytic anemia in the peripheral blood of beagles infected with B. gibsoni on the 2nd to the 3rd week post infection, induced by the destruction of red blood cells by parasites as they leave red blood cells. Similarly, a significant reduction in RBC and hemoglobin concentration was recorded by Bilwal et al. ${ }^{29}$, Adaszek et al. ${ }^{1}$ and Yogeshpriya et al. ${ }^{30}$ in dogs naturally infected with B. gibsoni when compared to apparently healthy dogs, as a result of antibody-mediated cytotoxic or non-immune mediated destruction of circulating red blood cells. In the present study, differences were obtained also between the two evaluated Babesia species, with markedly lower RBC values, $\mathrm{Hb}$ concentrations, as well as Hct values in dogs infected with B. gibsoni than in those with uncomplicated form of $B$. canis infection, suggesting a longer lasting process of red blood cell destruction by small $B$. gibsoni parasites. The complicated form of $B$. canis disease showed insignificant differences in the mean values of hematological parameters with lower values than in B. gibsoni infection.

The infection with B. gibsoni in dogs may cause several biochemical changes, but only limited studies are available on the analysis of pathological changes expressed as alterations in the protein pattern of the host to this infection, as well as on the possible differences between animals infected by different Babesia parasites. Bilwal et al. ${ }^{29}$ reported no significant differences in the values of total serum proteins between dogs with babesiosis and healthy dogs. Reddy et al. ${ }^{31}$ found in dogs infected with large Babesia parasites a significant reduction in total serum protein concentrations. On the other hand, Yogeshpriya et al. ${ }^{30}$ obtained in dogs naturally infected with $B$. gibsoni about $10 \mathrm{~g} / \mathrm{l}$ higher total serum protein values than in healthy dogs, but these differences were not significant. Presented study showed in dogs infected with B. gibsoni significantly higher total serum protein concentrations (about $20 \mathrm{~g} / \mathrm{l}$ higher) when compared to both forms of $B$. canis infected animals. These very high total serum protein values in dogs infected with $B$. gibsoni might be caused by markedly increased synthesis of globulins and probably reflect the response of the organism to severe chronic inflammation ${ }^{32}$, which is much more characteristic for the infection with B. gibsoni.

In general, significantly decreased concentrations of albumin were found by Yadav et al. ${ }^{33}$ and Vijayalakshmi et al. ${ }^{34}$ in dogs with babesiosis than in healthy dogs. Yogeshpriya et al. ${ }^{30}$ observed no marked differences in the albumin concentrations between dogs naturally infected with B. gibsoni and healthy dogs. On the other hand, the laboratory studies conducted by Adaszek et al. ${ }^{1}$ showed in dogs infected with B. gibsoni decreased concentrations of albumin. Even though the results of our study showed no marked differences in the absolute values of albumin between the dogs infected with B. gibsoni and all B. canis infected dogs, significantly lower mean value was recorded in the group of complicated form of $B$. canis infection compared to B. gibsoni group of dogs. The mean relative concentration of this protein fraction was significantly lower in the dogs infected with $B$. gibsoni (about $10 \%$ lower). This pattern was caused by significantly higher total serum protein concentrations in the $B$. gibsoni infected dogs. From these higher values calculated absolute concentrations of albumin showed in general no differences between the dogs infected with different Babesia parasites. The aforementioned lower relative concentrations of albumin in the B. gibsoni infected dogs might by related to glomerulonephritis and renal impairment due to the damage of renal cells by inflammatory mediators in the affected dogs, and consequent protein-losing nephropathy with glomerular leakage of proteins ${ }^{22,35}$. Furthermore, albumin has been termed as the major negative acute phase protein with markedly reduced synthesis during the acute phase response, seeing that the majority of amino acids are used mainly for the synthesis of positive acute phase proteins during the systemic inflammatory response caused by the infection ${ }^{12,36}$. The very low relative albumin concentrations 
in dogs infected with B. gibsoni suggest severe inflammatory processes with possible serious alterations in the affected dogs (despite no serious abnormalities and clinical signs suggestive of the infection).

The alterations in the serum protein electrophoretic pattern in dogs following natural infection with $B$. canis were studied previously by Maegraith et al. $^{37}$ and Tella and Maegraith ${ }^{38}$, and recently by Lobetti et al. ${ }^{39}$ and Tóthová et al. ${ }^{16}$, while a decrease in the relative concentrations of albumin was a typical finding in these studies. Furthermore, Tóthová et al. ${ }^{16}$ recorded significantly higher relative concentrations of $\alpha_{1^{-}}, \beta_{1^{-}}$and $\beta_{2^{-}}$globulins, and non-significantly higher values of $\alpha_{2}$-and $\gamma$-globulins in the affected dogs with a double $\alpha_{2}$-zone in six from thirty-seven evaluated animals. On the other hand, the findings of the study conducted by Lobetti et al. ${ }^{39}$ showed in dogs with mild and severe babesiosis low total serum proteins, albumin, A/G ratio and a-globulins, whereas dogs with complicated babesiosis had no typical alterations in the serum protein pattern. Changes in the serum protein pattern were observed also in dogs with Babesia annae infection, with differences depending on the presence or absence of azotaemia ${ }^{40}$. While the infected dogs without azotaemia had significantly higher total proteins and all the globulin fractions, and significantly lower albumin concentrations, the infected dogs with azotaemia showed significantly higher $\alpha_{1}$ - and $\alpha_{2}$-globulins, and significantly lower albumin values compared to the non-infected dogs. On the other hand, the changes in the serum protein pattern associated with $B$. gibsoni infections in dogs are still poorly understood, including the possible differences between $B$. gibsoni and $B$. canis infected dogs. In this study presented results showed in the dogs infected with $B$. gibsoni significantly lower relative concentrations of $\alpha_{1}$ - and $\alpha_{2}$-globulins when compared to B. canis infected dogs. The infection with Babesia parasites is associated with the development of systemic inflammatory responses, including the excessive release of inflammatory mediators and consequent increased production of acute phase proteins ${ }^{12}$. The results of the studies conducted by Matijatko et al. ${ }^{14}$ and Barić Rafaj et al. ${ }^{41}$ indicated that the natural infection with $B$. canis induced a marked acute phase response, characterized by higher concentrations of serum amyloid A that might be useful also in the monitoring of the response to treatment. Furthermore, some other proteins associated with the activation of host immune response were observed in $B$. canis infected dogs, including the increased synthesis of haptoglobin and ceruloplasmin ${ }^{13}$. The aforementioned acute phase proteins belong to the a-globulin fractions ${ }^{42}$, thus, the markedly higher concentrations of $\alpha_{1}$ - and $\alpha_{2}$-globulins obtained in the dogs infected with $B$. canis may reflect the increased production of acute phase proteins from these fractions. When compared to the $B$. canis infected dogs, the animals infected with B. gibsoni had significantly lower relative concentrations of $\alpha_{1}$ - and $\alpha_{2}$-globulins. Although an excessive proinflammatory activity was detected also in animals experimentally infected with $B$. gibsoni $i^{15}$, the increased synthesis of acute phase proteins from the $\alpha$-fractions was not yet described. Seeing that infections with B. gibsoni are rather chronic and more prolonged, the tissue damage and inflammation in the infected dogs might not evoke sufficient inflammatory response to give a more marked increase in the concentrations of proteins from this fraction, and thus it may not be detectable on serum protein electrophoresis. On the other hand, lower concentrations of $\alpha$-globulins in dogs with babesiosis may be caused by free hemoglobin due to intravascular haemolysis caused by the disease ${ }^{43,44}$. Furthermore, a double $\alpha_{2}$-zone was observable in our study in nine out of seventeen dogs infected with B. gibsoni (more than 50\%) with no visible hemolysis in the samples, and in six out of forty dogs infected with B. canis (15\%). Thus, this pattern of split $\mathrm{a}_{2}$-zone may suggest more severe intravascular haemolysis due to babesiosis or the presence of free hemoglobin (even in the absence of visible hemolysis). However, in the light of some contradictory data and due to missing or incomplete studies in the area of this research, further studies would be helpful to correctly explain these alterations. Some proteins from the $a$-fractions is difficult to separate electroforetically and identify due to their very low serum concentrations, therefore, the evaluation of individual serum proteins using other methods or immunoenzymatic assays are recommended.

In the relative concentrations of $\beta$-globulins, no significant differences were observed between the dogs infected with B. gibsoni and all dogs with $B$. canis infection, except for $\beta_{1}$-globulin fraction in complicated form of $B$. canis infection. The values were higher than those obtained by Tóthová et al. ${ }^{16}$ in clinically healthy dogs. The infection with Babesia parasites activates the mechanisms of the non-specific immune responses of the host, including the complement pathway with increased synthesis of complement components, especially $\mathrm{C} 3 \mathrm{a}^{45,46}$. Complement is involved also in the regulation of inflammatory processes ${ }^{47}$ and, thus, may be attributed to higher concentrations of $\beta$-globulins due to the infection with parasites and consequent tissue damage in the dogs with babesiosis when compared to healthy ones. C-reactive protein (CRP) is another protein that belongs to the $\beta$-globulin fraction. Based on the ability to react and the magnitude of its response during inflammatory processes, CRP was considered as the most sensitive and important positive acute phase protein in dogs with major diagnostic value ${ }^{48,49}$. Increased concentrations of CRP have been found in natural infection with $B$. canis caused by marked acute phase response ${ }^{14,41}$. It has been shown that CRP concentrations increase also in $B$. rossi and B. gibsoni infections ${ }^{13,15}$. The higher absolute concentrations of $\beta$-globulins in B. gibsoni infected dogs, comparable with those observed in B. canis infections, suggest strong association between the components of this fraction and the increased synthesis of some acute phase proteins from these fractions, despite the chronic nature of infections with B. gibsoni. However, it should be taken into consideration that the concentrations of acute phase proteins, as well as serum protein fractions might be related to the stage of the disease at the time of sample collection.

In the study presented by Ishimine et al. ${ }^{4}$, the beta- and gamma-globulins increased remarkably in dogs experimentally infected with B. gibsoni, and the $\gamma$-globulins remained higher until the 24 th week post infection. This increase was attributed to the humoral antibody responses against B. gibsoni, especially to the rapid increase of IgM and IgG immunoglobulins. Significantly increased concentrations of globulins in total were obtained also by Bilwal et al. ${ }^{29}$ in dogs naturally infected with B. gibsoni. When compared to dogs naturally infected with B. canis, presented study showed in dogs infected with B. gibsoni significantly higher relative concentrations of $\gamma$-globulins (approximately threefold higher). This pattern was characterized by higher and broad peaks in the $\gamma$-zone on the electrophoretogram, which might be attributed to the production of immunoglobulins (mainly 
IgG) directed against the invading agens and suggest chronic inflammatory processes and severe infection. Furthermore, as a consequence of antigenic stimulation by the Babesia parasites, the infected animals may produce also some other immunoglobulins, especially IgM or IgA in higher amounts ${ }^{50}$. These proteins may migrate into the $\beta$ region or $\beta-\gamma$ interzone and by overproduction may produce a beta-gamma fusion with no clear valley between these fractions ${ }^{51}$. This pattern, the so called $\beta-\gamma$ bridging was observable in two out of seventeen dogs infected with B. gibsoni. The above mentioned changes in the concentrations of protein fractions resulted also in alterations in the $\mathrm{A} / \mathrm{G}$ ratio. Decreased $\mathrm{A} / \mathrm{G}$ ratio was found in dogs with babesiosis when compared to apparently healthy animals ${ }^{29,33}$. Differences were obtained also between the dogs infected with different Babesia parasites, with significantly lower $\mathrm{A} / \mathrm{G}$ ratio in the animals infected with $B$. gibsoni than in $B$. canis infected dogs. The very low A/G ratios in the dogs infected with B. gibsoni were caused by decreased albumin concentrations and the overproduction of globulins.

\section{Conclusions}

In conclusion, the results indicate that the serum protein electrophoretic pattern in dogs are significantly altered both by $B$. gibsoni and B. canis infections, with different nature and magnitude of changes in the infected dogs according to the species of Babesia parasite involved in the infection. The obtained results suggest marked differences in the response of the organism to the infection caused by different Babesia parasites. When compared to infections with $B$. canis, characteristic alterations in the serum protein associated with B. gibsoni infection in dogs include significantly higher total serum proteins and $\gamma$-globulins, while the relative concentrations of albumin and $\mathrm{A} / \mathrm{G}$ ratio are markedly significantly lower. The results also suggest some differences when comparing the results of a group of dogs with B. gibsoni infection and evaluated forms of $B$. canis disease. Identification of those protein fractions whose serum concentrations undergo marked changes due to the infection with $B$. gibsoni may provide useful information for the understanding of metabolic and pathological processes occurring in the infected animals. Due to the increasing frequency of infections also in Europe, this study may be the first step towards further investigations of biochemical and metabolic changes in dogs infected with B. gibsoni.

\section{Material and methods}

Ethics declarations. This study was based on the standard clinical examination and blood sample collection. The blood samples were collected as per standard sampling procedure used without any harm to the animals. All procedures with animals in the study were conducted in accordance with the ethical standards and quidelines approved by the Committee of the University of Veterinary Medicine and Pharmacy in Košice on protection of animals used for scientific purposes and complied with the institutional requirements of the Code of Ethics for Scientists (Directive 74/2019/UVLF).

Animals and sample collections. Blood samples from seventeen client-owned dogs naturally infected with $B$. gibsoni were selected for this study. The evaluated dogs were American pit bull terriers of both genders (9 males and 8 females), their ages ranged from 1 to 5 years. Only pale mucouse membranes were observed by clinical examination in the evaluated dogs, no other abnormalities or signs suggestive of the infection were documented, and vital parameters were found to be normal. The dogs were fed in the standard way and regularly subjected to prophylaxis against ecto- and endo-parasites, and vaccinations against primary infectious diseases.

To compare the results between the two types of Babesia infections, forty dogs naturally infected with $B$. canis were also included into the study. They were admitted to the Clinic of Small Animals of the University of Veterinary Medicine and Pharmacy in Košice (Slovak Republic) with various clinical signs consisted with $B$. canis infection. Based on clinical symptoms and results of hematological and biochemical examinations aimed at diagnosing the occurrence of complications in the course of the disease, the dogs were divided into a group with uncomplicated (group UC, 25 dogs) and complicated (group C, 15 dogs) form of B. canis infection. Dogs with uncomplicated form of babesiosis presented lethargy, anorexia, weakness, pale mucous membrane, icterus, hemoglobinuria and splenomegaly. Complicated cases of disease were associated with signs of systemic inflammatory response syndrome ${ }^{52}$ and multiple organ dysfunction syndrome ${ }^{11}$, and seven dogs of this group died. These dogs were of various breeds and both genders ( 29 males and 11 females) at the age of 6 months to 14 years.

Blood samples were collected for hematological and biochemical analyses, microscopic evaluation of blood smears and in case of B. gibsoni polymerase chain reaction (PCR). Samples from the B. gibsoni infected dogs were taken by the veterinarian directly at the dog breeding site. The dogs infected with $B$. canis were sampled at the clinic at the time of admission before treatment was started. Permission to complete blood samples was obtained from each dog owner. Blood was for hematological examination collected from $v$. cephalica into tubes with potassium ethylenediamine tetraacetic acid (EDTA) as anticoagulant (Sarstedt, Nümbrecht, Germany). Blood samples for the biochemical examinations, including protein analyses were taken into serum gel separator tubes without any additives or anticoagulants (Sarstedt, Nümbrecht, Germany). These samples were centrifuged within $2 \mathrm{~h}$ after collection at $3000 \mathrm{~g}$ for $10 \mathrm{~min}$ and serum was transferred into plastic tubes. After the separation of sera, hemolysis was inspected. Hemolysis was present in 10 from 40 samples from dogs infected with B. canis. In samples from dogs infected with $B$. gibsoni no visible hemolysis was observed. One aliquot of the serum was dispensed into plastic tubes for protein analyses, and stored at $-20^{\circ} \mathrm{C}$ until it was analyzed.

Laboratory analyses. Diff-Quick stain (Medion Diagnostics AG, Düdingen, Switzerland) was used for the detection of Babesia organisms within red blood cells in the peripheral blood smears. The typical large pyriform parasites in the erythrocytes were identified as B. canis. The subspecies of $B$. canis were not detected. On the basis of the size of the intracellular parasites, the small forms of parasites observed in erythrocytes in blood smears 
were morphologically and morphometrically consistent with B. gibsoni, but the infection was confirmed by PCR using B. gibsoni specific primer.

Genomic DNA was extracted from $200 \mu \mathrm{L}$ of EDTA-blood samples, using a commercial DNA extraction kit (GeneJET PCR Purification Kit, ThermoFischer Scientific, Lithuania). For the molecular detection of Babesia spp., PCR amplification of approximately 450 bp long fragment of $18 \mathrm{~S}$ rRNA gene, spanned by a reverse BJ1 (5'GTCTTGTAATTGGAATGATGG3') and forward BN2(5'TAGTTTATGGTTAGGACTACG3') primer was performed according to Casati et al. ${ }^{53}$. Only positive samples were further screened for the presence of Babesia gibsoni by PCR using the primers Gib599F (5'CTCGGCTACTTGCCTTGTC3') and Gib1270R (5'GCCGAAACT GAAATAACGGC3'), which targeted a 671-bp long fragment of the $18 \mathrm{~S}$ rRNA gene ${ }^{54}$. In each PCR reaction, sequenced DNA from Babesia-positive dog was used as positive control and nucleases free water was added as the template in negative control. The PCR products were visualized by electrophoresis on $1.5 \%$ agarose gels stained with GoodView Nucleic Acid Stain (Beijing SBS Genetech, Beijing, China). All positive PCR products were purified using a purification kit (Qiagen, Hilden, Germany) and sequenced. Nucleotide sequences were manually edited in MEGA $6^{55}$ and further compared with GenBank entries by BLAST ${ }^{56}$. For the alignment of the homologous nucleotide sequences the Clustal W program was used.

Potassium-EDTA anticoagulated whole blood was used to assess the number of red blood cells (RBC, T/l), hemoglobin concentration $(\mathrm{Hb}, \mathrm{g} / \mathrm{dl})$ and packed cell volume (PCV, \%). Complete hematological analysis was done using the ProCyte Dx automated hematology analyzer (IDEXX Laboratories, Westbrook, Maine, USA). To evaluate the changes in the protein profile, serum samples were analyzed for the concentrations of total proteins and main protein fractions. The total protein concentrations (TP, g/l) were determined using an automated biochemical analyser Alizé (Lisabio, Poully en Auxois, France) according to the biuret method with commercially available diagnostic kits (Randox, Crumlin, United Kingdom). Zone electrophoresis on an agarose gel using an automated electrophoresis system Hydrasys and commercial diagnostic kits Hydragel 7 Proteine (Sebia Corporate, Lisses, Evry Cedex, France) was used for the separation of serum protein fractions ${ }^{57}$. The following protein fractions were identified: albumin, $\alpha_{1^{-}}, \alpha_{2^{-}}, \beta_{1^{-}}, \beta_{2^{-}}$and $\gamma$-globulins. They were expressed as relative values (\%) according to the optical density and their absolute concentrations $(\mathrm{g} / \mathrm{l})$ were quantified from the TP concentrations. The ratios of albumin to globulins $(\mathrm{A} / \mathrm{G})$ were calculated also. The values obtained from dogs infected with B. gibsoni were compared to those infected with B. canis.

Statistical analyses. The data obtained were subjected to statistical analysis. Descriptive statistical procedures were used to calculate arithmetic means (x) and standard deviations (SD) for each evaluated variable and group of dogs. The distribution of data was evaluated by Kolmogorov-Smirnov Test for normality. Not all the evaluated parameters showed normal distribution. Unpaired t-test was carried out to compare and evaluate the significance of differences in means between the B. gibsoni and B. canis infected dogs. The significance of differences in values between the B. gibsoni infected dogs and the uncomplicated and complicated forms of $B$. canis infections was evaluated using one-way ANOVA and Tukey-Kramer post-hoc test for normally distributed data and Kruskal-Wallis test with Dunn's Multiple Comparisons post-hoc test for non-normally distributed data. Variables with $P<0.05$ were considered as statistically significant. The statistical analyses were carried out by using the program GraphPad Prism V5.02 (GraphPad Software Inc., California, USA).

\section{Data availability}

The datasets generated and/or analysed during the current study are available from the corresponding author on reasonable request.

Received: 25 August 2020; Accepted: 19 October 2020

Published online: 03 November 2020

\section{References}

1. Adaszek, L. et al. The first case of Babesia gibsoni infection in a dog in Poland. Vet. Med. (Czech) 63, 225-228 (2018).

2. Irwin, P. J. Canine babesiosis: from molecular taxonomy to control. Parasites Vectors 2, 54 (2009).

3. Schoeman, J. P. Canine baesiosis. Onderstepoort J. Vet. Res. 76, 59-66 (2009).

4. Ishimine, T., Makimura, S., Kitazawa, S., Tamura, S. \& Suzuki, N. Pathophysiological findings on blood of beagles experimentally infected with Babesia gibsoni. Jpn. J. Trop. Med. Hyg. 6, 15-26 (1978).

5. Solano-Gallego, L., Sainz, A., Roura, X., Estrada-Peña, A. \& Miró, G. A review of canine-babesiosis: the European perspective. Parasites Vectors 9,336 (2016).

6. Irwin, P. J. Canine babesiosis. Vet. Clin. N. Am. Small Anim. Pract. 40, 1141-1156 (2010).

7. Solano-Gallego, L. \& Baneth, G. Babesiosis in dogs and cats-expanding parasitological and clinical spectra. Vet. Parasitol. 181, $48-60$ (2011).

8. MacIntire, D. K. et al. Babesia gibsoni infection among dogs in the southeastern United States. J. Am. Vet. Med. Assoc. 220, 325-329 (2002).

9. Birkenheuer, A. J., Correa, M. T., Levy, M. G. \& Breitschwerdt, E. B. Geographic distribution of babesiosis among dogs in the United States and association with dog bites: 150 cases (2000-2003). J. Am. Vet. Med. Assoc. 227, 942-947 (2005).

10. Jefferies, R. et al. Blood, bull terriers and babesiosis: further evidence for direct transmission of Babesia gibsoni in dogs. Aust. Vet. J. 85, 459-463 (2007).

11. Welzl, C., Leisewitz, A. L., Jacobson, L. S., Vaughan-Scott, T. \& Myburgh, E. Systemic inflammatory response syndrome and multiple-organ damage/dysfunction in complicated canine babesiosis. J. S. Afr. Vet. Assoc. 72, 156-162 (2011).

12. Schetters, T. P. M. et al. Systemic inflammatory responses in dogs experimentally infected with Babesia canis; a haematological study. Vet. Parasitol. 162, 7-15 (2009).

13. Ulutas, B., Bayramli, G., Ulutas, P. A. \& Karagenc, T. Serum concentration of some acute phase proteins in naturally occurring canine babesiosis: a preliminary study. Vet. Clin. Pathol. 34, 144-147 (2005).

14. Matijatko, V. et al. Evidence of an acute phase response in dogs naturally infected with Babesia canis. Vet. Parasitol. 144, 242-250 (2007). 
15. Brown, A. L., Shiel, R. E. \& Irwin, P. J. Clinical, haematological, cytokine and acute phase protein changes during experimental Babesia gibsoni infection of beagle puppies. Exp. Parasitol. 157, 185-196 (2015).

16. Tóthová, C. et al. The electrophoretic pattern of serum proteins in dogs with babesiosis. Acta Vet. (Brno) 88, 425-432 (2019).

17. Hartelt, K. et al. First evidence of Babesia gibsoni (Asian genotype) in dogs in Western Europe. Vector Borne Zoonotic Dis. 7, 163-166 (2007).

18. Davitkov, D. et al. Clinical babesiosis and molecular identification of Babesia canis and Babesia gibsoni infections in dogs from Serbia. Acta Vet. Hung. 63, 199-208 (2015).

19. Meinkoth, J. H., Kocan, A. A., Loud, S. D. \& Lorenz, M. D. Clinical and hematologic effects of experimental infection in dogs with recently identified Babesia gibsoni-like isolates from Oklahoma. J. Am. Vet. Med. Assoc. 220, 185-189 (2002).

20. Köster, L. S., Lobetti, R. G. \& Kelly, P. Canine babesiosis: a perspective on clinical complications, biomarkers, and treatment. Vet. Med. Res. Rep. 6, 119-128 (2015).

21. Boozer, L. \& Macintire, D. Babesia gibsoni: an emerging pathogen in dogs. Comp. Cont. Educ. Pract. Vet. 27, 33-42 (2005).

22. Wozniak, E. J. et al. Clinical, anatomic, and immunopathologic characterization of Babesia gibsoni infection in the domestic dog (Canis familiaris). J. Parasitol. 83, 692-699 (1997).

23. Bilić, P., Kuleš, J., Barić Rafaj, R. \& Mrljak, V. Canine babesiosis: where do we stand?. Acta Vet. (Beograd) 68, 127-160 (2018).

24. Furlanello, T., Fiorioa, F., Caldina, M., Lubasb, G. \& Solano-Gallegoa, L. Clinicopathological findings in naturally occurring cases of babesiosis caused by large form Babesia from dogs of northeastern Italy. Vet. Parasitol. 134, 77-85 (2005).

25. Maele, I. V., Bataille, K. S., Gielen, I. \& Darninet, S. An unusual form of canine babesiosis. Can. Vet. J. 49, 283-286 (2008).

26. Kumar, P. \& Kumar, A. Haemato-biochemical changes in dogs infected with Babesiosis. Int. J. Chem. Stud. SP4, 25-28 (2018)

27. Ristic, M., Lykins, J. D. \& Smith, A. R. Babesia canis and Babesia gibsoni, soluble and corpuscular antigen isolated from blood of dogs. Exp. Parasitol. 30, 385-392 (1971).

28. Noda, R. Canine babesiosis. J. Jpn. Vet. Med. Assoc. 30, 247-251 (1977).

29. Bilwal, A. K., Mandali, G. C. \& Tandel, F. B. Clinicopathological alterations in naturally occurring Babesia gibsoni infection in dogs of Middle-South Gujarat, India. Vet. World 10, 1227-1232 (2017).

30. Yogeshpriya, S. et al. Clinical, haemato-biochemical and ultrasonographical studies on naturally occurring Babesia gibsoni infection in dogs. J. Entomol. Zool. Stud. 6, 1334-1337 (2018).

31. Reddy, B. S., Sivajothi, S., Reddy, L. S. S. \& Raju, K. G. S. Clinical and laboratory findings of Babesia infection in dogs. J. Parasit. Dis. 40, 268-272 (2016).

32. Vavricka, S. R., Burri, E., Beglinger, C., Degen, L. \& Manz, M. Serum protein electrophoresis: an underused but very useful test. Digestion 79, 203-210 (2009).

33. Yadav, R., Gattani, A., Gupta, S. R. \& Sharma, C. S. Jaundice in dogs associated with babesiosis-a case report. Int. J. Agric. Vet. Med. Sci. 5, 3-6 (2011).

34. Vijayalakshmi, P. et al. Clinico pathological features in dogs associated with babesiosis. Indian Vet. J. 91, 21-24 (2014).

35. Zygner, W. \& Wedrychowicz, H. Influence of anemia on azotaemia in dogs infected with Babesia canis in Poland. Bull. Vet. Inst. Pulawy 53, 663-668 (2009).

36. Aldred, A. R. \& Schreiber, G. The Negative Acute Phase Protein. In Acute Phase Proteins. Molecular Biology, Biochemistry, and Clinical Applications (eds Mackiewicz, I. et al.) 21-37 (CRC Press, Boca Raton, 1993).

37. Maegraith, B., Gilles, H. M. \& Devakul, K. Pathological processes in Babesia canis infections. Z. Tropenmed. Parasitol. 8, 485-514 (1957).

38. Tella, A. \& Maegraith, B. G. Physiopathological changes in primary acute blood-transmitted malaria and Babesia infections. II. A comparative study of serum protein levels in infected rhesus monkeys, mice and puppies. Ann. Trop. Med. Parasitol. 59, 153-158 (1965).

39. Lobetti, R. G., Mohr, A. J., Dippenaar, T. \& Myburgh, E. A preliminary study on the serum protein response in canine babesiosis. J. S. Afr. Vet. Assoc. 71, 38-42 (2000).

40. Camacho, A. T. et al. Serum protein response and renal failure in canine Babesia annae infection. Vet. Res. 36, 713-722 (2005).

41. Barić Rafaj, R. et al. Markers of coagulation activation, endothelial stimulation, and inflammation in dogs with babesiosis. J. Vet. Int. Med. 27, 1172-1178 (2013)

42. Ceron, J. J., Caldin, M. \& Martinez-Subiela, S. Answers to some common questions on serum protein electrophoresis. Vet. Rec. 168, 453-454 (2011)

43. Martinez-Subiela, S., Tecles, F., Montes, A., Gutiérrez, C. \& Cerón, J. J. Effects of haemolysis, lipaemia, bilirubinaemia, and fibrinogen on protein electrophoretogram of canine samples analysed by capillary zone electrophoresis. Vet. J. 164, 261-268 (2002).

44. Zygner, W., Gójska-Zygner, O. \& Wẹdrychowicz, H. Abnormalities in serum proteins in the course of babesiosis in dogs. Bull. Vet. Inst. Pulawy 55, 59-65 (2011).

45. Zygner, W., Rapacka, G., Gójska-Zygner, O., Dlugosz, E. \& Wẹdrychowicz, H. Biochemical abnormalities observed in serum of dogs infected with large Babesia in Warsaw (Poland). Pol. J. Vet. Sci. 10, 245-253 (2007).

46. Kuleš, J. et al. Identification of serum biomarkers in dogs naturally infected with Babesia canis canis using a proteomic approach. BMC Vet. Res. 10, 111-120 (2014).

47. Jacobson, R. H., Parrodi, F., Wright, I. G., Fitzgerald, C. J. \& Dobson, C. Babesia bovis: in vitro phagocytosis promoted by immune serum and and by antibodies produced against protective antigens. Parasitol. Res. 79, 221-226 (1993).

48. Yamamoto, S. et al. Isolation of canine C-reactive protein characterization of its properties. Vet. Immunol. Immunopathol. 30, 329-399 (1992).

49. Eckersall, P. D. \& Bell, R. Acute phase proteins: Biomarkers of infection and inflammation in veterinary medicine. Vet. J. 185, 23-27 (2010).

50. Kaneko, J. J. Serum Proteins and the Dysproteinemias. In Clinical Biochemistry of Domestic Animals 5th edn (ed. Kaneko, J. J.) 117-138 (Academic Press, London, 1997).

51. Morris, D. \& Johnston, J. K. Alterations in Blood Proteins. In Large Animal Internal Medicine 3rd edn (ed. Smith, B. P.) 426-433 (Mosby, St. Louis, 2002).

52. Okano, S. et al. Usefulness of systemic inflammatory response syndrome criteria as an index for prognosis judgement. Vet. Rec. 150, 245-246 (2002)

53. Casati, S., Sager, H., Gern, L. \& Piffaretti, J. C. Presence of potentially pathogenic Babesia sp. for human in Ixodes ricinus in Switzerland. Ann. Agric. Environ. Med. 13, 65-70 (2006).

54. Miyama, T. et al. Epidemiological survey of Babesia gibsoni infection in dogs in eastern. Jpn J. Vet. Med. Sci. 67, 467-471 (2005).

55. Tamura, K., Stecher, G., Peterson, D., Filipski, A. \& Kumar, S. MEGA6: molecular evolutionary genetics analysis version 6.0. Mol. Biol. Evol. 30, 2725-2729 (2013).

56. Altschul, S. F. et al. Gapped BLAST and PSI-BLAST: a new generation of protein database search programs. Nucleic Acids Res. 25, 3389-3402 (1997).

57. Nagy, O., Tóthová, C., Nagyová, V. \& Kováč, G. Comparison of serum protein electrophoretic pattern in cows and small ruminants. Acta Vet. (Brno) 84, 187-195 (2015). 


\section{Acknowledgements}

This work was supported by the grants No. VEGA 1/0398/18 and VEGA 1/0314/20 from the Ministry of Education, Science, Research and Sport of the Slovak Republic and the Internal grant agency of the University of Veterinary Medicine and Pharmacy in Košice No. 15/2019.

\section{Author contributions}

C.T.: Conceptualization, Formal analysis, Writing_original draft. M.K.: Conceptualization, Investigation. L.B.: Methodology. M.F.: Validation. O.N.: Data curation, Supervision, Writing-review \& editing. All authors contributed to the study conception and design. All authors read and approved the final manuscript.

\section{Competing interests}

The authors declare no competing interests.

\section{Additional information}

Correspondence and requests for materials should be addressed to C.T.

Reprints and permissions information is available at www.nature.com/reprints.

Publisher's note Springer Nature remains neutral with regard to jurisdictional claims in published maps and institutional affiliations.

(c) (i) Open Access This article is licensed under a Creative Commons Attribution 4.0 International License, which permits use, sharing, adaptation, distribution and reproduction in any medium or format, as long as you give appropriate credit to the original author(s) and the source, provide a link to the Creative Commons licence, and indicate if changes were made. The images or other third party material in this article are included in the article's Creative Commons licence, unless indicated otherwise in a credit line to the material. If material is not included in the article's Creative Commons licence and your intended use is not permitted by statutory regulation or exceeds the permitted use, you will need to obtain permission directly from the copyright holder. To view a copy of this licence, visit http://creativecommons.org/licenses/by/4.0/.

(c) The Author(s) 2020 